\title{
Effect of Cavity Position, Size and Geometry on Partial Discharge Behaviour inside 18/30 kV XLPE Cables
}

\author{
Essam M. Shaalan ${ }^{1}$, Sayed A. Ward ${ }^{2}$, and Ahmed Youssef ${ }^{3}$ \\ ${ }^{1}$ Electrical Eng. Dep., Faculty of Engineering at Shoubra, Benha University Cairo, Egypt \\ ${ }^{2}$ Vice Dean, Faculty of Eng., Delta University for Science and Technology, Mansoura, Egypt \\ ${ }^{3}$ South Cairo Electrical Distribution Company, Giza, Egypt \\ essam.shihata@feng.bu.edu.eg, sayed.ward@feng.bu.edu.eg, ahmadyoussef2018@gmail.com
}

\begin{abstract}
Cross-linked polyethylene (XLPE) is increasingly used for medium to high voltage distribution cables for their excellent mechanical, thermal and electrical performance. However, the existence of impurities/voids inside this insulting material represents the major problem when it is used as insulation in cables due to the occurrence of partial discharge (PD). Therefore, this study investigated the effect of existence of such impurities/voids inside 18/30 kV XLPE cables on the activities of PD. Moreover, the effect of changing the cavity position, size and geometry on the partial discharge behaviour was studied. Also, the potential gradient and the electric field distribution across this insulating material were obtained and analyzed during different operating conditions using COMSOL program. The simulation results of our study are nearly matched with measurements performed by others related to our study. The simulation results verified that; nearest the cavity to the core causes higher electric field potential and decrease with increasing the cavity distance from the cable core. This is in addition to the larger the size of cavity the higher the electric field potential and consequently fasting the activities of PD.
\end{abstract}

Keywords: XLPE Cables; Partial discharge; Cavity; Electric Field distribution; COMSOL.

\section{Introduction}

XLPE has gradually replaced the other polyethylene in the manufacture of medium and high voltage cables recently thanks to its excellent electrical and thermal properties compared to Low density Polyethylene. Currently, XLPE is used as an insulator for high voltage and extra high voltage cables ranging from $275 \mathrm{kV}$ to $500 \mathrm{kV}$ [1-5].

The cable faults can be classified into several types, but the most common type is due to the existence of air voids and impurities in the insulating material during the manufacturing process or during the installation of the cable accessories which may have different geometrical shape such as rectangular, spherical, elliptical, cylindrical etc. leading to occurrence of partial discharges and resulting in cable insulation failure. Therefore, the partial discharge is nearly the most important cause for the medium voltage cables faults $[6,7]$.

These voids are generally filled with a medium of lower dielectric strength than that of the insulating material and having a relative permittivity less than that of the insulating material, Therefore the electric field strength inside the void will be much greater than that effecting on the insulating material, even under normal operating condition the electric field inside the void is greater than the breakdown value, which causes localized breakdown inside the void [7].

The partial discharge occurred inside the void will create free electrons and positive ions with high energy sufficient to break the chemical bond of the insulating material when reaching the void surfaces. Moreover, every discharge will raise the temperature of the void resulting in the carbonization of the void surface and creating a conducting tree like structures channels and pits on the insulation surface which increasing the conductivity and causing cable thermal aging and increasing the void pressure and hence the partial discharge activity increased. Also, Chemical degradation may be occurred due to the active discharge products formed during the repeated partial discharges which will limit the cable effective service life because the life of the insulation with internal partial discharge depends upon the applied voltage and number of discharges [712].

Received: March $7^{\text {th }}, 2021$. Accepted: June $24^{\text {th }}, 2021$ DOI: $10.15676 /$ ijeei.2021.13.2.15 
All these effects will cause gradual erosion for the insulating material and enlargement of the cavities and consequent reduction in the thickness of the insulation, after a period of time it will degrade the quality of the insulation resulting in the total breakdown [12].Therefore, the existence of impurities/voids inside this insulting material represents the major problem when it is used as insulation in cables, as it causes un expected cable faults, resulting in the unavailability of power for a long time till the detection of the fault location and isolation of its causes; from our field experience this time may take from 30 to 90 minutes until reenergizing the power again, in addition to at least three hours to repair and test the cable to restore it into the service. Finally, the electrical power needs to be disconnected again to reenergize the cable after repairing it to return it into the service. The repeated cut-off of electrical power will result in an annoyed customer. Therefore, in this paper the effect of existence of impurities/voids inside $18 / 30 \mathrm{kV}$ XLPE Cables will be investigated. Moreover, the effect of changing the cavity position, size and geometry on the partial discharge behaviour will be studied and analyzed to determine the most suitable precaution recommended during cable system installation and manufacturing to reduce the undesired cable system faults, to prevent the occurrence of faults rather than the system restoring after fault occurrence.

\section{Description of Practical Case under Study}

This study was done on a practical $18 / 30 \mathrm{kV}$ XLPE medium voltage cable which already exist in October and New Cairo medium voltage networks and operated normally at operating voltage of $22 \mathrm{kV}$. Table 1 shows the geometrical parameters of the cable under study as shown in Figure 1. These parameters were taken throughout our simulation to configure and model this cable using COMSOL program as follows:

- Conductor Radius $=9.2 \mathrm{~mm}$.

- Conductor + Cond. Screen $=11 \mathrm{~mm}$.

- Conductor + Cond. Screen + XLPE insulation $=18.6 \mathrm{~mm}$.

- Conductor + Cond. Screen + XLPE insulation + insulation Screen $=21.1 \mathrm{~mm}$.

- Conductor + Cond. Screen + XLPE insulation + insulation Screen + Earthing Screen = 21.9 $\mathrm{mm}$.

Table 1. Geometrical Parameters of $18 / 30 \mathrm{kV}$ XLPE Cable

\begin{tabular}{|l|c|}
\hline \multicolumn{1}{|c|}{ Parameters } & Dimension (mm) \\
\hline Conductor diameter (D1) & 18.4 \\
\hline Inner/conductor screen thickness (T1) & 1.8 \\
\hline XLPE Insulation thickness (T2) & 7.6 \\
\hline Outer/insulation screen thickness (T3) & 2.5 \\
\hline Earthing screen (Tape) thickness (T4) & 0.8 \\
\hline Bedding thickness (T5) & 1.3 \\
\hline Armour Wire diameter (T6) & 2.5 \\
\hline Overall/Jacket diameter (D2) & 49 \\
\hline
\end{tabular}

Table 2. the relative permittivity of material used for of $18 / 30 \mathrm{kV}$ XLPE Cable [13]

\begin{tabular}{|c|c|}
\hline Material & Relative permittivity \\
\hline Copper & 1 \\
\hline XLPE & 2.3 \\
\hline Semiconducting material & 2.3 \\
\hline Air & 1.006 \\
\hline
\end{tabular}




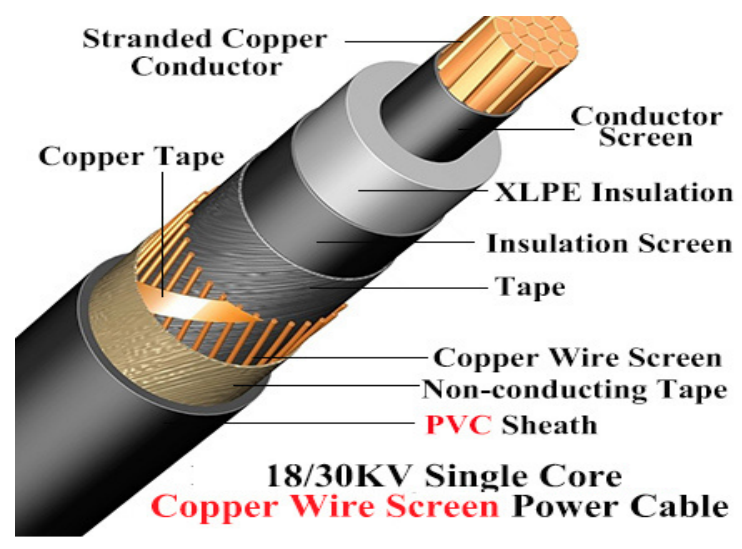

Figure 1. XLPE insulated medium voltage cable construction.

The simulation model of this XLPE insulated armored sheath cable has been designed with their respective material and respective parameters, Table 2 shows the relative permittivity of the cable materials. The Bedding and outer PVC jacket are ignored in our simulation because they have not any effects in our study as the potential of Earthing Screen is putted with $0 \mathrm{~V}$ as a boundary condition.

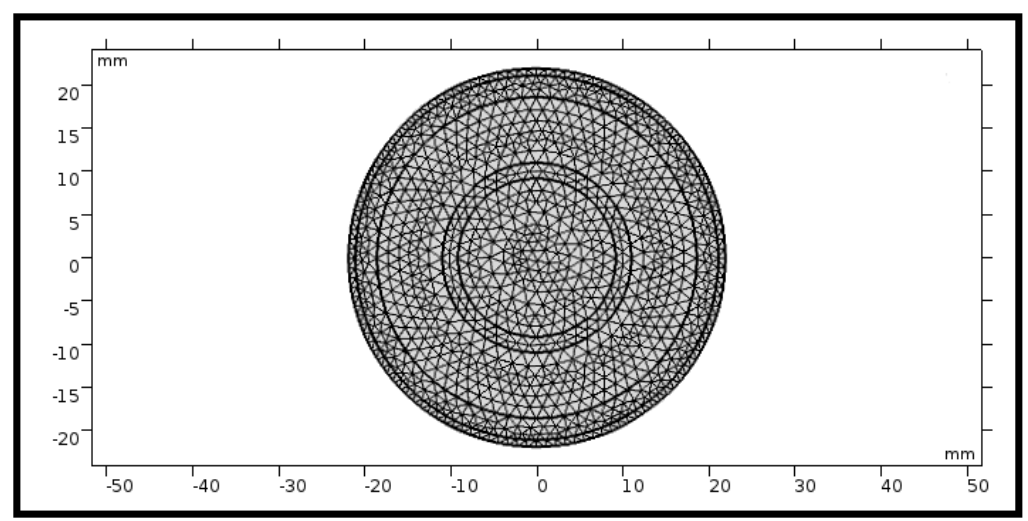

(a)

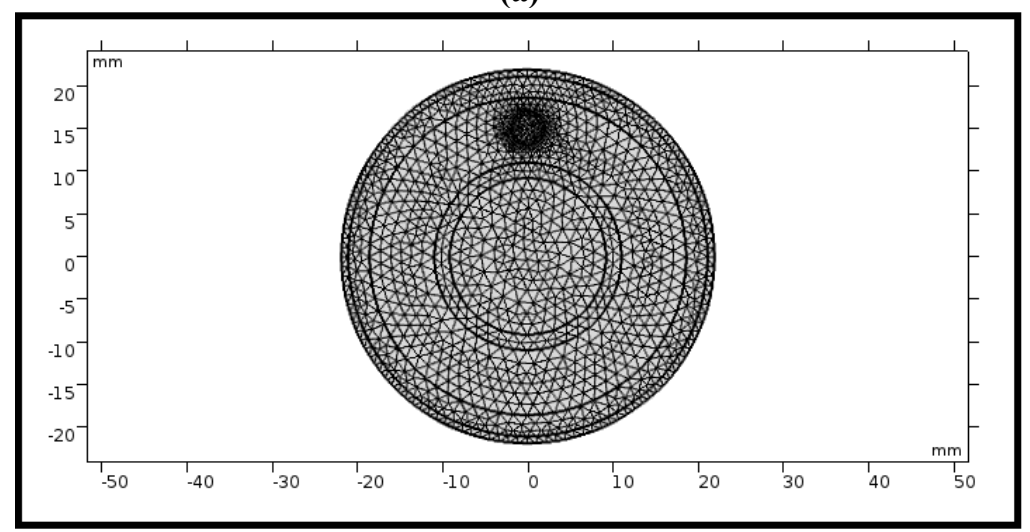

(b)

Figure 2. (a) Healthy $18 / 30 \mathrm{kV}$ single core cable model, (b) $18 / 30 \mathrm{kV}$ single core cable with $2 \mathrm{~mm}$ air void model divided by finer mesh model. 
The COMSOL program will solve the numerical model of the voltage and the electric field distribution across the cable layers which are built by the finite element method (FEM) where the model designed is transformed into a mesh of many elements. The voltage and the electric field values are computed at every point in the model. To improve the accuracy of the solution results the model is divided using the finer mesh model which contains more mesh nodes as shown in Figure 2-a and Figure 2-b for a healthy cable model, for a cable model having a $2 \mathrm{~mm}$ air void inside the XLPE insulation. However, a larger number of mesh nodes yields longer simulation times.

Finally the cable models under study are implemented in COMSOL Multi physics software to obtain the potential distribution and electric field distribution across this model using mathematical equations (e.g. equation No. 1) and energy minimization in triangular elements related to the finite element method [14].

$-\nabla(\sigma+\partial \mathcal{E} / \partial \mathrm{t}) \nabla \mathrm{V}=0$

where $\sigma$ is the conductivity of the material, $\varepsilon$ is the material permittivity and $V$ is the electric potential.

\section{Simulation Results and Discussions}

The effect of existence of impurities/voids inside 18/30 kV XLPE Cables was investigated by simulating and modelling of this cable once without cavities; to study the electric potential and the electric field distribution across the different layers of the cable components at normal case; and the other with the existence of cavities to study the effect of cavity on Partial Discharge behaviour inside this Cable. Moreover, the effect of cavity position, size, and geometry on Partial Discharge behaviour inside this Cable was investigated.

These simulation results were compared with measurements performed by others in literatures $[13,15,16]$. The simulation results and discussions are as follow:

\section{A. Simulation Results of a Healthy Cable}

The simulated model of cable is performed for a healthy cable (without cavities) to show the electric potential and the electric field distribution across the different layers of the cable components at normal case without cavities as shown in Figure 3-a and Figure 3-b. From these figures it is noted that the electric potential and the electric field is normally distributed across different cable layers with a maximum value occurred adjacent to the conductor which is not exceeding the breakdown strength of the cable insulation.

\section{B. Simulation Results of a Cable Having a Cavity under Normal Operating Conditions}

The simulated model of cable is performed for a cable with a cavity inside the cable insulation to show the electric potential and the electric field distribution across the different layers of the cable components at normal operating conditions. Moreover, the effect of cavity position, size and geometry on Partial Discharge behaviour inside this Cable was investigated.

\section{1) A spherical air cavity with different sizes and positions}

The cavity is considered as a spherical void having a fixed radius of $1 \mathrm{~mm}$ and changing the cavity position to study the effect of changing the cavity position. The electric potential and the electric field distribution across the cable layers are shown in Figure 4-a , Figure 4-b, Figure 5a , Figure 5-b, Figure 6-a, Figure 6-b Figure 7-a and Figure 7-b ,. From these figures, it is found that the maximum value of electric field strength is occurred inside the cavity when it is adjacent to the inner semi-conductor layer and it decreases with increasing the cavity distance from the cable conductor.

To study the effect of changing the cavity size, the cavity is considered as a spherical void having different radii of $0.5 \mathrm{~mm}$ and $2 \mathrm{~mm}$ (half and Twice) and the cavity is located at the same four positions considered previously. Table 3 shows the maximum and minimum values of electric field strength inside the cable under these cases. From this table, it is noticed that the maximum value of electric field strength is occurred inside the cavity of radius $=0.5 \mathrm{~mm}$ when it is adjacent 
to the inner semi-conductor layer and it slightly decreases with increasing the cavity radius. But the partial discharges will be occurred on a great space inside the insulation. Therefore, the most severe case is of the cavity having $\mathrm{r}=2 \mathrm{~mm}$ when it is adjacent to the inner semi-conductor surface, because the insulation thickness is small, the cavity has large surface area offering large number of free electrons which will gain energy; from the high electric field strength inside the cavity; sufficient to cause repeated electrical discharges causing insulation deterioration inside the cavity and leading to the total breakdown after very short time. It is noted that this result show a good coincidence with conclusions of related experimental studies [15].

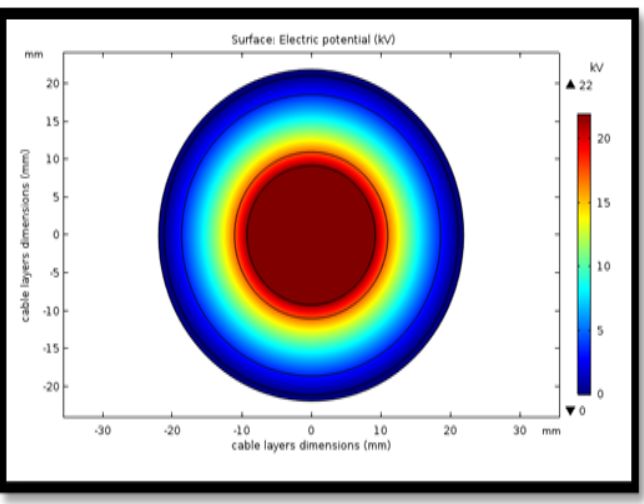

(a)

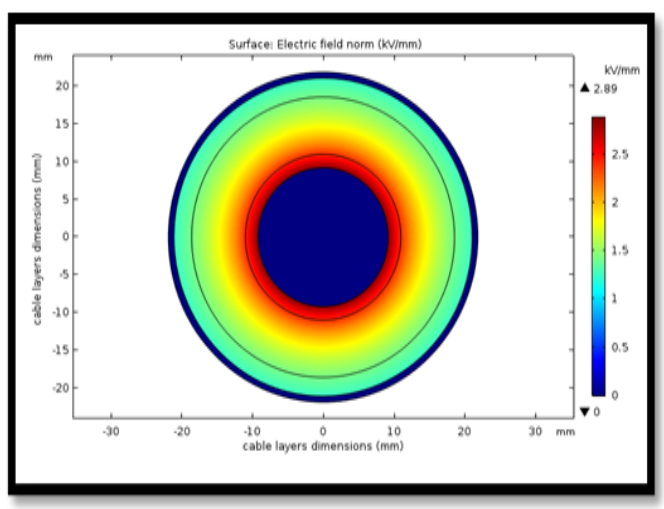

(b)

Figure 3. (a) Electric potential distribution, (b) Electric field distribution for healthy $18 / 30 \mathrm{kV}$ single core cable.

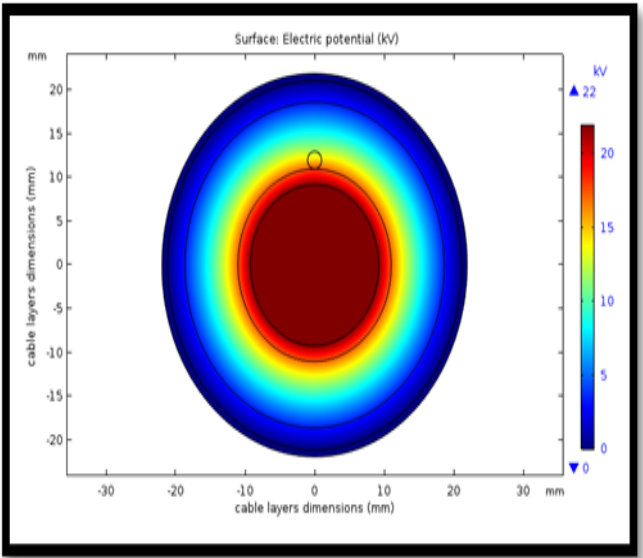

(a)

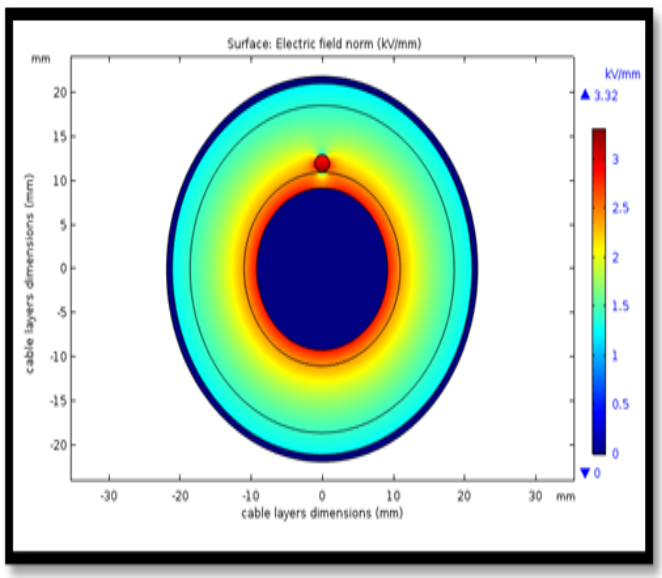

(b)

Figure 4. (a) Electric potential distribution, (b) Electric field distribution for $18 / 30 \mathrm{kV}$ single core cable with a spherical air cavity of $1 \mathrm{~mm}$ radius adjacent to the inner semi-conductor layer. 


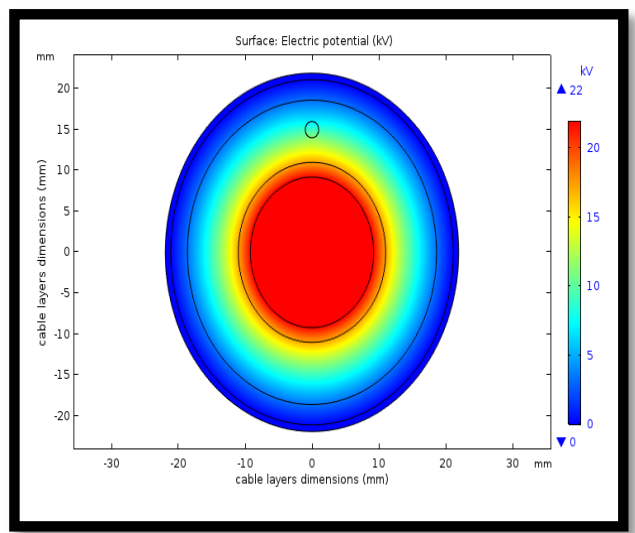

(a)

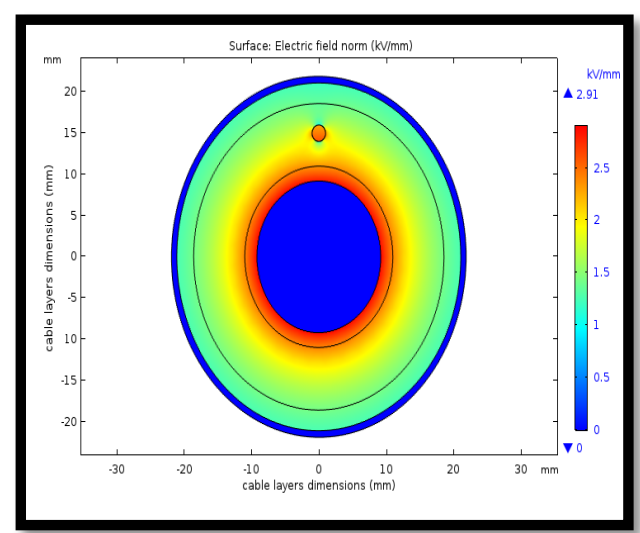

(b)

Figure 5. (a) Electric potential distribution, (b) Electric field distribution for $18 / 30 \mathrm{kV}$ single core cable with a spherical air cavity of $1 \mathrm{~mm}$ radius at the center of the XLPE insulation layer.
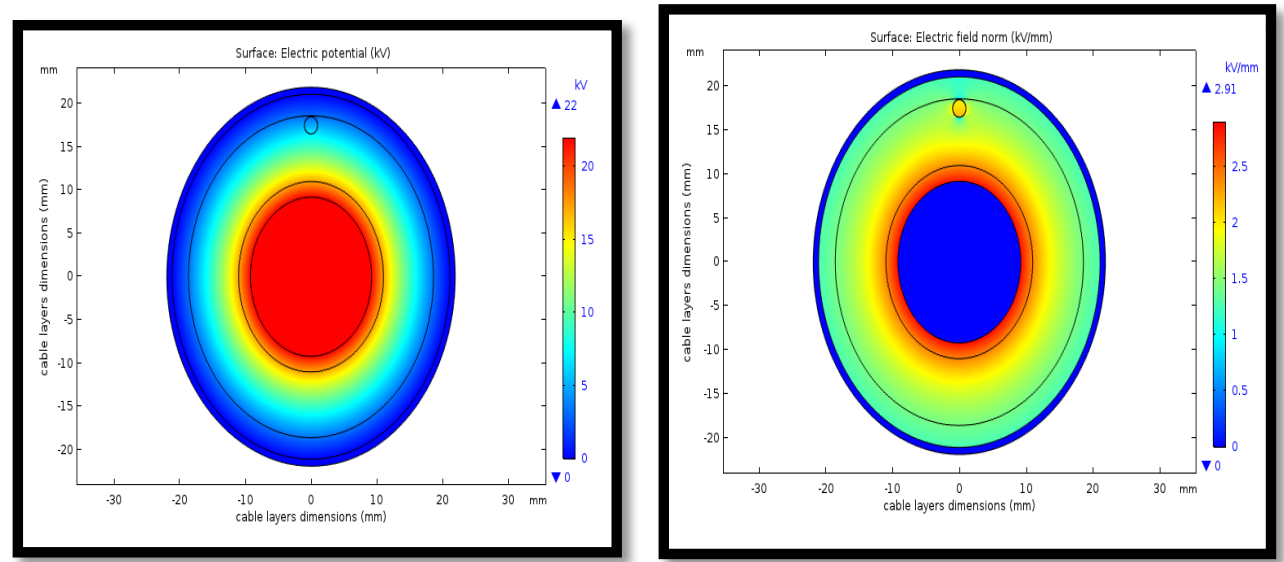

Figure 6. (a) Electric potential distribution, (b) Electric field distribution for $18 / 30 \mathrm{kV}$ single core cable with a spherical air cavity of $1 \mathrm{~mm}$ radius adjacent to the outer semi-conductor layer.

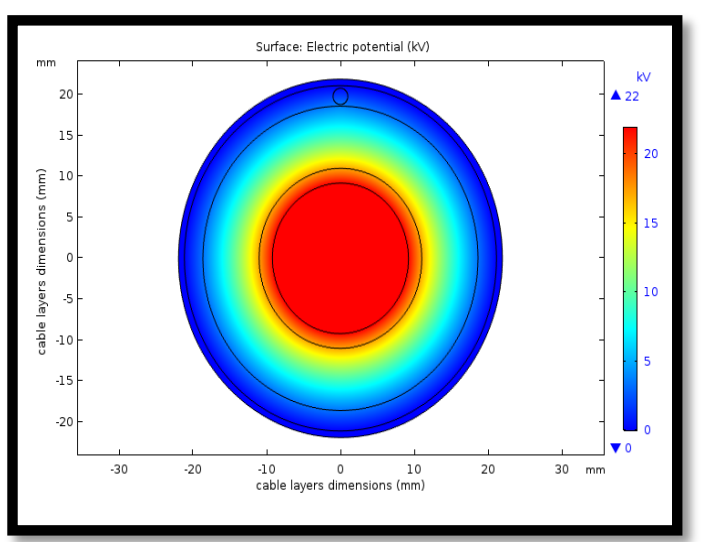

(a)

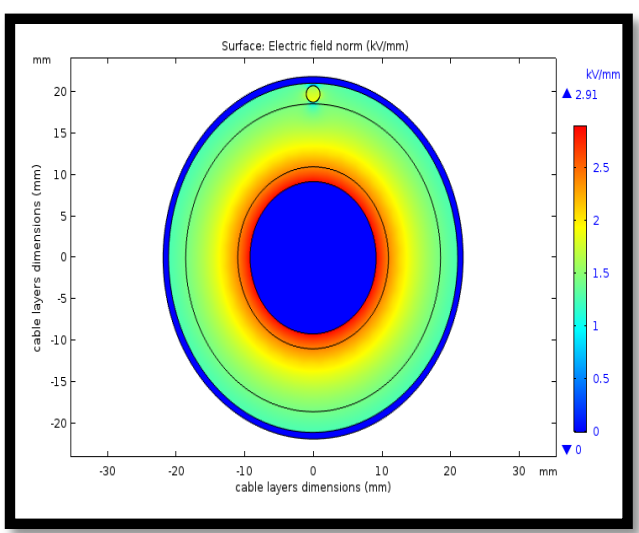

(b)

Figure 7. (a) Electric potential distribution, (b) Electric field distribution for $18 / 30 \mathrm{kV}$ single core cable with a spherical air cavity of $1 \mathrm{~mm}$ radius inside the outer semi-conductor layer. 
Table 3: The Maximum and Minimum Values of Electric Field Strength Inside a Cable Having a Spherical Cavity of $r=0.5 \mathrm{~mm}, \mathrm{r}=1 \mathrm{~mm}$ and $\mathrm{r}=2 \mathrm{~mm}$.

\begin{tabular}{|c|c|c|c|c|c|c|c|c|}
\hline \multirow{2}{*}{$\begin{array}{c}\begin{array}{c}\text { Cavity } \\
\text { Position }\end{array} \\
\text { E } \\
(\mathbf{k V} / \mathbf{m m})\end{array}$} & \multicolumn{2}{|c|}{$\begin{array}{l}\text { Adjacent to the } \\
\text { inner semi- } \\
\text { conductor } \\
\text { layer }\end{array}$} & \multicolumn{2}{|c|}{$\begin{array}{l}\text { Center of the } \\
\text { XLPE } \\
\text { insulation layer }\end{array}$} & \multicolumn{2}{|c|}{$\begin{array}{l}\text { Adjacent to } \\
\text { the outer } \\
\text { semi- } \\
\text { conductor } \\
\text { layer }\end{array}$} & \multicolumn{2}{|c|}{$\begin{array}{l}\text { Inside the } \\
\text { outer semi- } \\
\text { conductor } \\
\text { layer }\end{array}$} \\
\hline & $\mathbf{E}_{\max }$ & $E_{\min }$ & $E_{\max }$ & $\mathbf{E}_{\min }$ & $E_{\max }$ & $\mathbf{E}_{\min }$ & $\mathbf{E}_{\max }$ & $\mathbf{E}_{\min }$ \\
\hline $\mathrm{r}=0.5 \mathrm{~mm}$ & 3.37 & 1.54 & 2.7 & 1.17 & 2.12 & $\begin{array}{c}1.00 \\
5\end{array}$ & ------ & ----- \\
\hline $\mathrm{r}=\mathbf{1} \mathrm{mm}$ & 3.32 & 1.3 & 2.6 & 1.03 & 2.2 & 0.87 & 1.9 & 0.95 \\
\hline $\mathrm{r}=\mathbf{2 m m}$ & 3.18 & 1.05 & 2.53 & 0.96 & 2.1 & 0.6 & ------- & -----. \\
\hline
\end{tabular}

\section{2) Changing the air cavity geometry}

To study the effect of changing the cavity geometry, the cavity is considered as a cubic and ellipsoid void having a different sizes and positions. Firstly, the air cavity is simulated as a cube having a side length of $L=1.6 \mathrm{~mm}$ to give the same volume of a spherical cavity with radius $\mathrm{r}$ $=1 \mathrm{~mm}$, then the cube side length was increased to be $\mathrm{L}=3.22 \mathrm{~mm}$ to give the same volume of a spherical cavity with radius $r=2 \mathrm{~mm}$. Finally, the air cavity is simulated as an ellipsoid of $\mathrm{a}=3$ $\mathrm{mm}, \mathrm{b}=1 \mathrm{~mm}$ and $\mathrm{c}=2.66 \mathrm{~mm}$ to give the same volume of a spherical cavity with radius $\mathrm{r}=$ $2 \mathrm{~mm}$. The selected cavity is located at the same four positions considered previously. Table 3 shows the maximum and minimum values of electric field strength inside the simulated cable under these cases, with different sizes, geometries and positions. From this table, it is noted that the maximum value of electric field strength is occurred inside the cubic cavity of side length $\mathrm{L}$ $=3.22 \mathrm{~mm}$ when it is adjacent to the inner semi-conductor layer. This is because there is a large wide area subjected to the electric field lines propagated from the conductor surface and due to sharp edges, there will be strong partial discharges on large space inside the insulation. It is noticed also that the maximum value of electric field strength is occurred with a cubic cavity and it decreases with an ellipsoid cavity and it has a lowest value with a spherical cavity. The effect of changing the cavity geometry on the electric field distribution across the cable layers; when the cavity is adjacent to the inner semi-conductor layer; are shown in Figure 8, Figure 9 , Figure 10, and Figure 11 at center of XLPE insulation. It is noted that this result show a good coincidence with conclusions of related experimental studies [15].

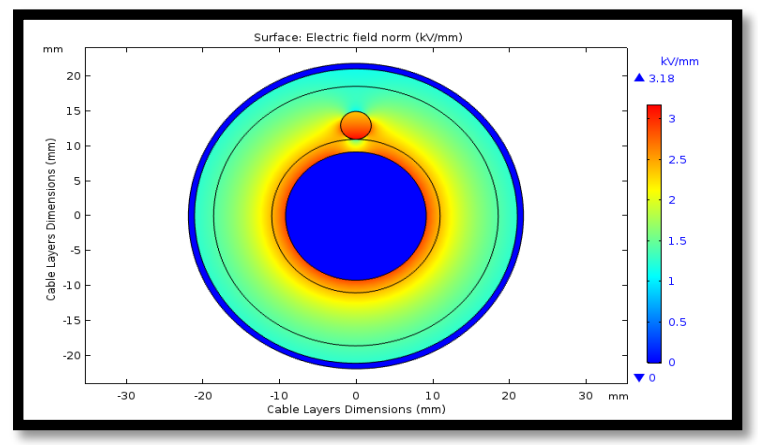

Figure 8. Electric field distribution for $18 / 30 \mathrm{kV}$ single core cable with a spherical air cavity of $2 \mathrm{~mm}$ radius adjacent to the inner semi-conductor layer. 
Essam M. Shaalan, et al.

Table 4. The Maximum and Minimum Values of Electric Field Strength Inside a Cable Having a Cavity with different geometries, Sizes and locations.

\begin{tabular}{|c|c|c|c|c|c|c|c|c|c|}
\hline $\begin{array}{l}\text { Cavity } \\
\text { Geomet } \\
\text { ry }\end{array}$ & $\begin{array}{c}\text { Cavity } \\
\text { Position }\end{array}$ & \multicolumn{2}{|c|}{$\begin{array}{c}\text { Adjacent to } \\
\text { the inner } \\
\text { semi- } \\
\text { conductor } \\
\text { layer }\end{array}$} & \multicolumn{2}{|c|}{$\begin{array}{l}\text { Centre of the } \\
\text { XLPE } \\
\text { insulation } \\
\text { layer }\end{array}$} & \multicolumn{2}{|c|}{$\begin{array}{l}\text { Adjacent to } \\
\text { the outer } \\
\text { semi- } \\
\text { conductor } \\
\text { layer }\end{array}$} & \multicolumn{2}{|c|}{$\begin{array}{l}\text { Inside the } \\
\text { outer semi- } \\
\text { conductor } \\
\text { layer }\end{array}$} \\
\hline \multicolumn{2}{|c|}{ E $(\mathrm{kV} / \mathrm{mm})$} & $\mathbf{E}_{\max }$ & $\mathbf{E}_{\min }$ & $\mathbf{E}_{\max }$ & $\mathbf{E}_{\min }$ & $\mathbf{E}_{\max }$ & $\mathbf{E}_{\min }$ & $\mathbf{E}_{\max }$ & $\mathbf{E}_{\min }$ \\
\hline \multirow{3}{*}{$\begin{array}{l}\text { Spheric } \\
\text { al Air } \\
\text { Cavity }\end{array}$} & $\mathrm{r}=0.5 \mathrm{~mm}$ & 3.37 & 1.54 & 2.7 & 1.17 & 2.12 & 1.005 & ----- & ------ \\
\hline & $\mathrm{r}=\mathbf{1} \mathrm{mm}$ & 3.32 & 1.3 & 2.6 & 1.03 & 2.2 & 0.87 & 1.9 & 0.95 \\
\hline & $r=2 \mathrm{~mm}$ & 3.18 & 1.05 & 2.53 & 0.96 & 2.1 & 0.6 & - & - \\
\hline \multirow{2}{*}{$\begin{array}{l}\text { Cubic } \\
\text { Air } \\
\text { Cavity }\end{array}$} & $\mathrm{L}=1.6 \mathrm{~mm}$ & 3.7 & 1.57 & 2.73 & 1.3 & 2.3 & 1 & 2.89 & 1.2 \\
\hline & $\begin{array}{c}\mathrm{L}=3.22 \mathrm{~m} \\
\mathrm{~m}\end{array}$ & 3.86 & 1.23 & 3.13 & 1 & 2.55 & 0.98 & 2.89 & 1.1 \\
\hline $\begin{array}{l}\text { Ellipsoi } \\
\text { d Air } \\
\text { Cavity }\end{array}$ & $\begin{array}{c}a * b * c \\
3 * 1 * 2.66 \\
\mathrm{~mm}\end{array}$ & 3.84 & 1.74 & 3.13 & 1.75 & 2.52 & 1.09 & 2.91 & 1.14 \\
\hline
\end{tabular}

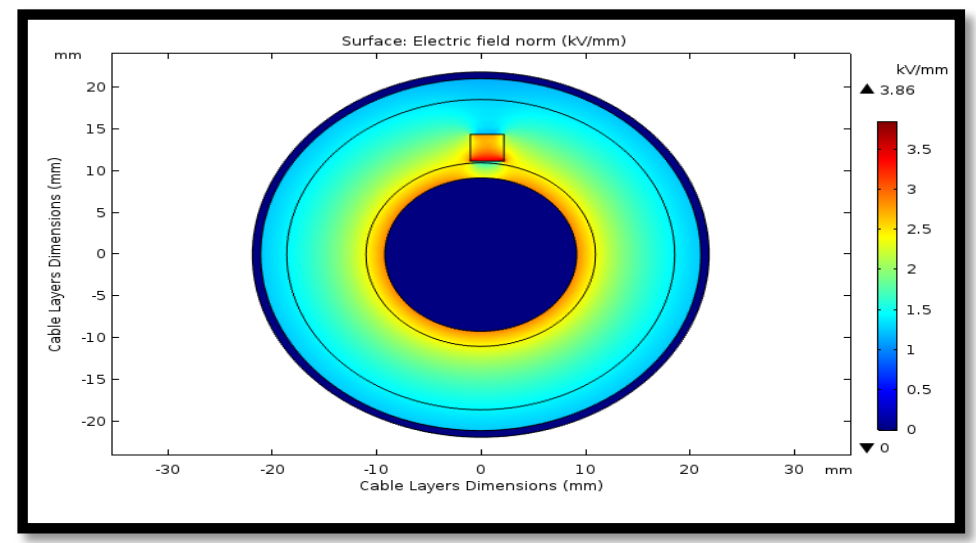

Figure 9. Electric field distribution for $18 / 30 \mathrm{kV}$ single core cable with a cubic air cavity of $\mathrm{L}=$ $3.22 \mathrm{~mm}$ adjacent to the inner semi-conductor layer. 


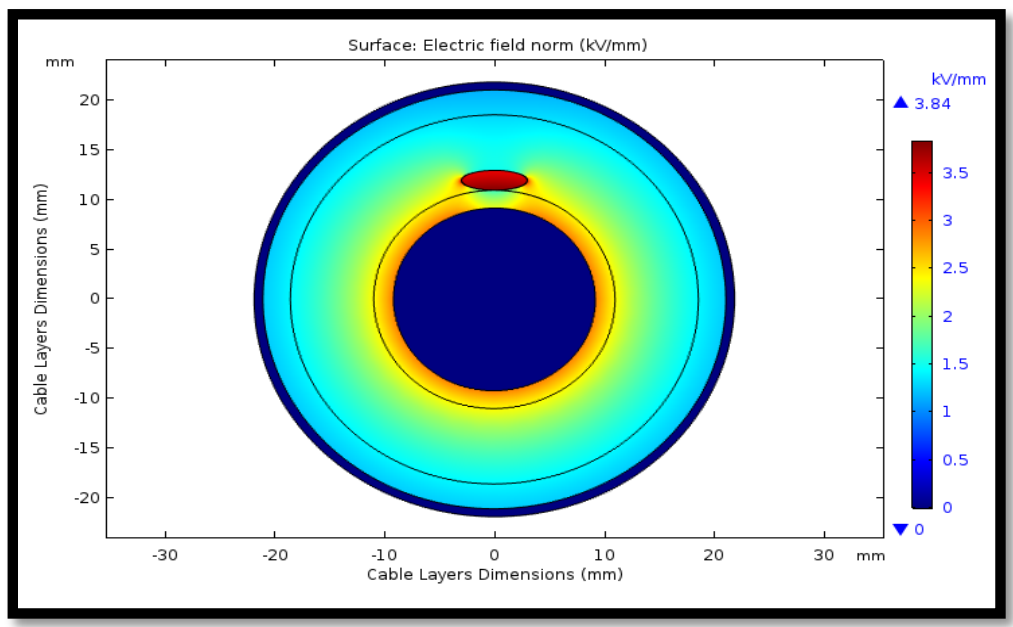

Figure 10. Electric field distribution for $18 / 30 \mathrm{kV}$ single core cable with an ellipsoidal air cavity of $3 * 1 * 2.66$ adjacent to the inner semi-conductor layer.

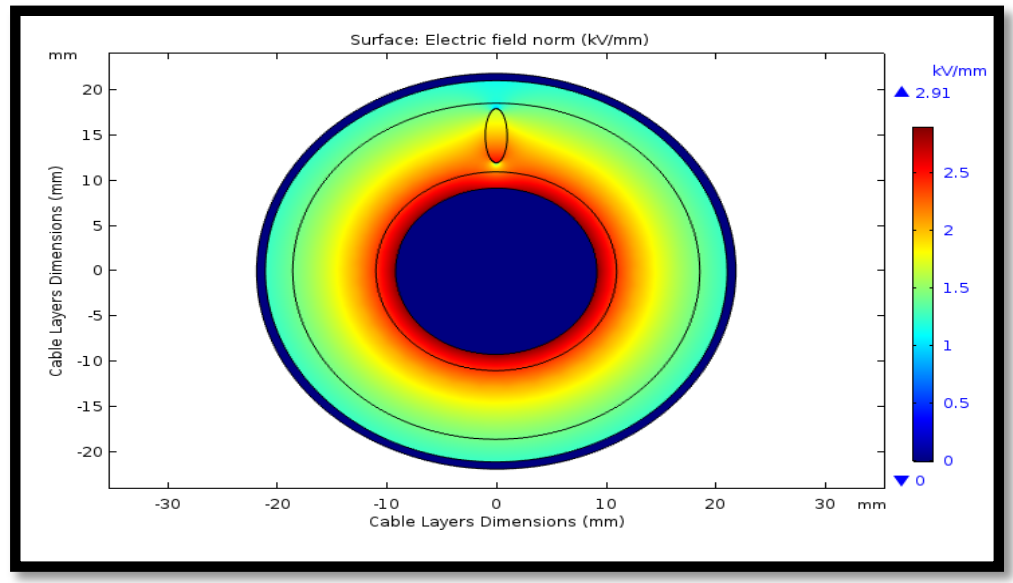

Figure 11. Electric field distribution for $18 / 30 \mathrm{kV}$ single core cable with an vertical ellipsoidal air cavity of $3 * 1 * 2.66 \mathrm{~mm}$ at the center of the XLPE insulation.

\section{Cable Having a Cavity under Critical Over Voltage}

During the operation of the electrical power system, the cables may suffer from temporary over-voltage. Therefore, our study not only performed during normal operating conditions (at normal operating voltage of $22 \mathrm{kV}$ ), but also it is performed under temporary over-voltages. To study the effect of temporary over-voltage on the cable having cavity, The simulated model of cable is performed for a cable with air cavity as an ellipsoid of $\mathrm{a}=3 \mathrm{~mm}, \mathrm{~b}=1 \mathrm{~mm}$ and $\mathrm{c}=2.66$ $\mathrm{mm}$ and this cable is subjected to over voltage of $1.36 \mathrm{U}_{\mathrm{o}}(30 \mathrm{kV})$, the electric potential and the electric field distribution across the cable layers in this case are shown in Figure 12-a and Figure 12-b.

Table 5 shows the maximum and minimum values of electric field strength inside the simulated cable having cavities with different sizes, geometries, and positions under normal operating voltage $\left(\mathrm{U}_{\mathrm{o}}=22 \mathrm{kV}\right)$ and under abnormal operating condition; temporary over-voltage; $\left(1.36 \mathrm{U}_{0}=30 \mathrm{kV}\right)$. From these figures and table, it is noted that increasing the voltage to $30 \mathrm{kV}$ will increase the electric field to very high value inside the cavity causing very high partial discharges rate, which may lead to fast breakdown; decreasing the time to the total break down dramatically and also decreasing the cable lifetime. 


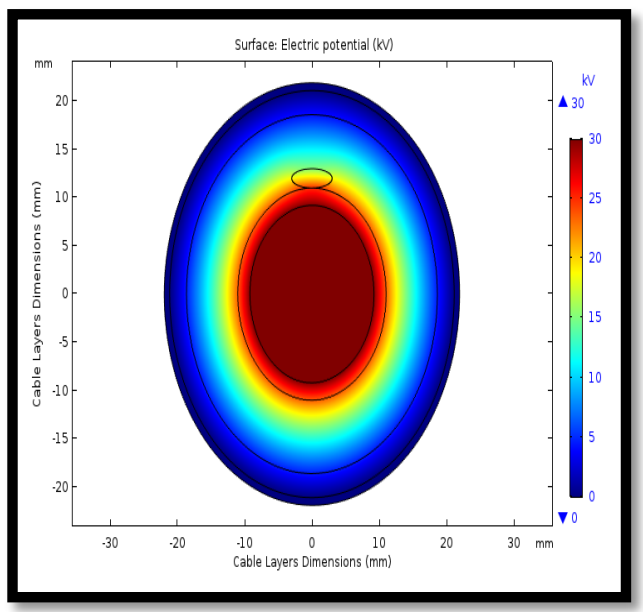

(a)

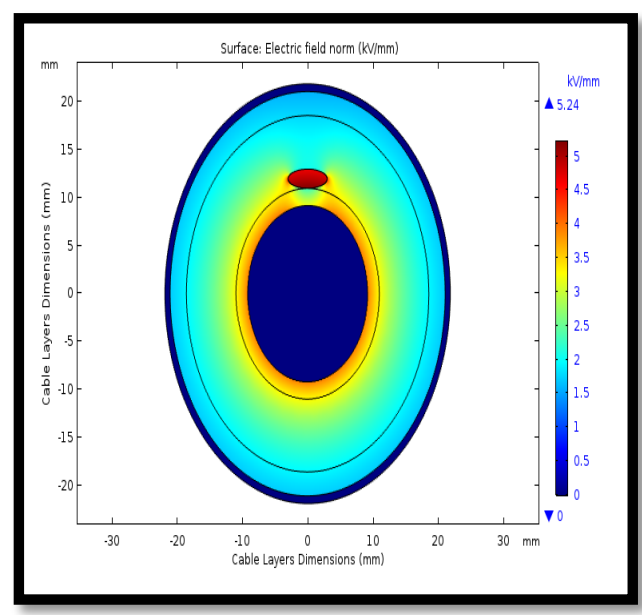

(b)

Figure 12. (a) Electric potential distribution, (b) Electric field distribution for $18 / 30 \mathrm{kV}$ single core cable with an ellipsoidal air cavity of $3 * 1 * 2.66 \mathrm{~mm}$ adjacent to the inner semi-conductor layer and subjected to $30 \mathrm{kV}$.

Table 5. The Maximum and Minimum Values of Electric Field Strength Inside a Cable having an ellipsoidal air cavity of $3 * 1 * 2.66 \mathrm{~mm}$ and subjected to normal operating voltage $(\mathrm{Uo}=22$

$\mathrm{kV})$ and abnormal operating condition; temporary over-voltage of $(1.36 \mathrm{Uo}=30 \mathrm{kV})$.

\begin{tabular}{|c|c|c|c|c|c|}
\hline $\begin{array}{c}\text { Cavity } \\
\text { Geometry }\end{array}$ & $\begin{array}{l}\text { Applied } \\
\text { Voltage }\end{array}$ & \multicolumn{2}{|c|}{$\begin{array}{c}\text { Cavity Adjacent } \\
\text { to the inner } \\
\text { semi-conductor } \\
\text { layer }\end{array}$} & \multicolumn{2}{|c|}{$\begin{array}{l}\text { Cavity inside the } \\
\text { outer semi- } \\
\text { conductor layer }\end{array}$} \\
\hline \multicolumn{2}{|c|}{ E $(\mathrm{kV} / \mathrm{mm})$} & $\mathbf{E}_{\max }$ & $\mathbf{E}_{\min }$ & $\mathbf{E}_{\max }$ & $\mathbf{E}_{\min }$ \\
\hline \multirow{2}{*}{$\begin{array}{c}\text { Ellipsoid Air } \\
\text { Cavity with } \\
a * b * c \\
3 * 1 * 2.66 \mathrm{~mm}\end{array}$} & $\mathrm{U}_{0}=22 \mathrm{kV}$ & 3.84 & 1.74 & 2.91 & 1.14 \\
\hline & $\begin{array}{c}1.36 \mathrm{U}_{\mathrm{o}}=30 \\
\mathrm{kV}\end{array}$ & 5.24 & 2 & 4 & 1.55 \\
\hline
\end{tabular}

\section{Conclusion and Recommendations}

The presence of air void inside the XLPE insulation will create hot spots with very high electric field strength leading to repeated partial discharges inside the cavity causing deterioration for the insulating material and leading to insulation total break down after period.

From the modelling and simulating of the cable with different cavity size, geometry and positions it is noted that the electric field strength inside the cavity is maximum when it is adjacent to the inner semi-conductor layer and decrease with increasing the cavity distance from the cable conductor; the concentration of electrical field is higher around the cavity near to conductor core compared to the other one away from conductor core.

Additionally, it is found that increasing the volume of the air void will slightly decrease the maximum electric field values, but the partial discharges will be on a large space inside the insulation which might be due to larger development of the avalanche head within large size of the cavity. Finally, it is found that the cavity geometry has a great effect on the electric field strength inside the cavity, while the highest electric field strength is occurred with a cubic cavity and it decreases with an ellipsoid cavity and it has a lowest value with a spherical cavity.

It is noticed also as shown in Table 6 that all obtained results give a good coincidence with conclusions of related experimental studies. 
Table 6. Our Simulation Results Vs Related Experimental Results carried out on a sample of $18 / 30 \mathrm{kV}$, XLPE, $400 \mathrm{~mm}^{2}$ single core cable.

\begin{tabular}{|c|c|c|}
\hline & Our Simulation Results & $\begin{array}{c}\text { Related Experimental Results } \\
\text { carried out on a sample of } 18 / 30 \\
\mathrm{kV}, \text { XLPE, } 400 \mathrm{~mm}^{2} \text { single core } \\
\text { cable }[15]\end{array}$ \\
\hline $\begin{array}{l}\text { Effect of } \\
\text { cavity } \\
\text { position }\end{array}$ & $\begin{array}{l}\text { The electric field strength inside the } \\
\text { cavity is having maximum value when it } \\
\text { is adjacent to the inner semi-conductor } \\
\text { layer and decrease with increasing the } \\
\text { cavity distance from the cable } \\
\text { conductor. }\end{array}$ & $\begin{array}{l}\text { Not mentioned in Experimental } \\
\text { works which is the novelty of our } \\
\text { study. }\end{array}$ \\
\hline $\begin{array}{c}\text { Effect of } \\
\text { cavity size }\end{array}$ & $\begin{array}{l}\text { Increasing the volume of the air void } \\
\text { will slightly decrease the maximum } \\
\text { electric field values, but the partial } \\
\text { discharges will be on a large space } \\
\text { inside the insulation which might be due } \\
\text { to larger development of the avalanche } \\
\text { head within large size of the cavity }\end{array}$ & $\begin{array}{l}\text { changing the size of cavity does } \\
\text { not give significant change in } \\
\text { Partial Discharge Inception } \\
\text { Voltage (PDIV) and increase of PD } \\
\text { amplitude as a function of voltage } \\
\text { is steeper for the bigger size of } \\
\text { cavity. }\end{array}$ \\
\hline $\begin{array}{l}\text { Effect of } \\
\text { cavity } \\
\text { geometry }\end{array}$ & $\begin{array}{l}\text { The cavity geometry has a great effect } \\
\text { on the electric field strength inside the } \\
\text { cavity, while the highest electric field } \\
\text { strength is occurred with a cubic cavity } \\
\text { as a result of the cube sharp edges, and } \\
\text { it decreases with an ellipsoid cavity, and } \\
\text { it has a lowest value with a spherical } \\
\text { cavity }\end{array}$ & $\begin{array}{l}\text { The PD magnitude increases with } \\
\text { increasing the voltage with } \\
\text { different shape of the artificial } \\
\text { cavities. }\end{array}$ \\
\hline
\end{tabular}

Most of the previous researchers in this field study the partial discharge practically, but as the occurrence of an actual void inside the cable insulation is accidentally, therefore achieving these study practically is not accurate, e.g. creating avoid practically will require drilling the outer surface of the cable which creating a leakage path between the inner surface of the void and the outer semiconductor layer surface resulting in a hollow not a void. Moreover they also simulate the void as a hollow, but this study take the actual void configuration, location and shape to simulate and study the effect of voids size, position and shape on the PD inside the cable insulation with very high accuracy, that is helping us in the actual understand of PD in the cables,

\section{References}

[1]. Z. Ahmed, J. V. Kluss, and D. A. Wallace, "Partial discharge measurements and techniques for pattern recognition and life prediction of medium voltage XLPE cables," IEEE International Conference on High Voltage Engineering and Application, pp. 1-4, 2018.

[2]. J.V. Gulmine, L. Akcelrud, "Correlations between structure and accelerated artificial ageing of XLPE", European Polymer Journal, Vol. 42, No. 3, pp. 553-562, 2006.

[3]. C. Kim, Z. Jin, X. Huang, P. Jiang, and Q. Ke, "Investigation on water treeing behaviors of thermally aged XLPE cable insulation", Polymer Degradation and Stability, Vol. 92, No. 4, pp. 537-544, April 2007.

[4]. C. Vanga-Bouanga, H. Couderc, M.F. Fréchette, et al, "Dielectric study of low glass transition temperature cycloaliphatic UV-curable epoxy networks", IEEE Transactions on Dielectrics and Electrical Insulation, Vol. 19, No. 4, pp. 1269-1282, 2012. 
[5]. L. Boukezzi, A. Boubakeur, "Prediction of mechanical properties of XLPE cable insulation under thermal aging", IEEE Transactions on Dielectrics and Electrical Insulation, Vol. 20, No. 6, pp. 2125-2134, December 2013.

[6]. P.Hyvönen, "Prediction of Insulation Degradation of Distribution Power Cables Based on Chemical Analysis and Electrical Measurements", PhD. dissertation, Dep. Elect. Eng., Helsinki Univ. of Technology, Espoo, Finland, 2008.

[7]. Asima Sabat and S. Karmakar, "Simulation of Partial Discharge in High Voltage Power Equipment", International Journal on Electrical Engineering and Informatics, Volume 3, Number 2, 2011.

[8]. M S Naidu, V Kamaraju, "High Voltage Engineering", third edition,TataMcGraw-hill publication, ch4, pp.95-97, seventh reprint 2005.

[9]. Larbi Boukezzi, Ahmed Boubakeur, et al," Observations on structural changes under thermal ageing of cross-linked polyethylene used as power cables insulation",iranian Polymer Journal, Vol. 17. No. 8, PP. 611-624, August 2008.

[10]. J. Gulmine and L. Akcelrud, "FTIR characterization of aged XLPE", Polymer Testing, vol.25, no.7, pp. 932-942, October 2006.

[11]. A. Z. Abdullah, M. N. K. H. Rohani, M. Isa, H. Hamid, S. N. M. Arshad, and M. Othman, "Real On-Site Partial Discharge Measurement Technique in Medium Voltage Power Cable," IEEE $7^{\text {th }}$ International Conference on Power and Energy, pp. 405-408, 2018.

[12]. Suwarno, "Partial Discharge in High Voltage Insulating Materials", International Journal on Electrical Engineering and Informatics, Volume 8, Number 1, March 2016.

[13]. Osama E. Gouda, Adel El-Faraskoury and Abd Rabu Elsinnary, et al, "Investigating the effect of cavity size within medium voltage power cable on partial discharge behaviour", IET Generation, Transmission and Distribution, Vol. 12, No. 5, PP. 1190 - 1197, November 2017.

[14]. Hadi, N.A., Zulkurnain, A., Saeed, V.M., et al.: 'Three dimensional potential and electric field distributions in HV cable insulation containing multiple cavities', Advanced Materials Research, 2014, 845, pp. 372-377.

[15]. Adel El-Faraskoury and Ossama Gouda, "Partial Discharge Measurements with Internal Artificial Cavities Defects for Underground Cables", $16^{\text {th }}$ International Middle- East Power Systems Conference MEPCON'2014, Ain Shams University, Cairo, Egypt, December 23 $25,2014$.

[16]. Isa M A M, Rohani M N K H, Mustafa W A, et al, "Investigation on partial discharge activities in cross-linked polyethene power cable using finite element analysis", Journal of Physics: Conference Series 1432:012024, January 2020.

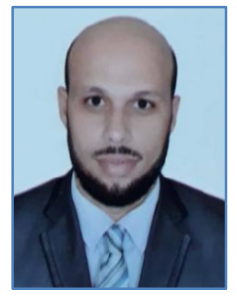

Essam M. Shaalan, Essam was born in Cairo, Egypt, on January 12, 1985. He received the B.Sc. M.Sc. and Ph.D. degrees in electrical engineering with honor in 2007, 2011 and 2015 respectively from Benha University, Shoubra, Cairo, Egypt. He is currently lecturer at Electrical Engineering Department, Faculty of Engineering (Shoubra), Cairo, Egypt. His research activity includes studying the high voltage electric fields, Human Exposure to electric fields. Gas Insulated Switchgear, Transformer Oil Characteristics \& Performance and Hazards Due To HV Transmission lines and power cables. 


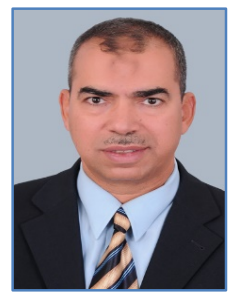

Sayed Abo-Elsood Ward, Ward was born in Cairo, Egypt, on December 24, 1961. He received the B.Sc. degree in electrical engineering with honor in 1984 and the M.Sc. degree in high-voltage Engineering in 1988, both from Zagazig University, Shoubra, Cairo, Egypt. He received the Ph. D. degree in highvoltage engineering in 1992 from Cairo University. He is currently a Vice Dean, Faculty of Eng., Delta University for Science and Technology, Mansoura, Egypt. His research activity includes studying the gas discharge phenomena in GIS, breakdown in Insulating Oils and DGA oil analysis in transformers.

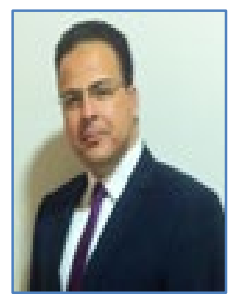

Ahmad Youssef, Ahmad received BSc from The Department of Electrical Engineering, Shoubra faculty of engineering, Benha University, Cairo, Egypt in 2008. He is working as electrical testing engineer at south Cairo electrical distribution company (SCEDC), Dokky electrical distribution networks. His research interests are High Voltage Insulating Materials, Partial Discharge Study, fault location techniques and High Voltage Industrial Application. 